\section{Primary bilateral malignant melanoma of the lower limbs}

\author{
Serena Lembo, ${ }^{1}$ Matteo Megna, ${ }^{1}$ \\ Paolo Maddalena, ${ }^{2}$ Ambra Monfrecola, ${ }^{1}$ \\ Anna Balato, ${ }^{1}$ Antonello Baldo' \\ 'Department of Dermatology, University \\ of Naples Federico II, Naples, Italy; \\ ${ }^{2}$ Surgery Department, A.S.L. 5, Hospital \\ of Sorrento, Naples, Italy
}

\begin{abstract}
Malignant melanoma is the eighth most common cancer in European women. Its incidence is increasing rapidly and it has been demonstrated that this is related to sun exposure. Although few cases of bilateral uveal or choroidal melanoma are described in literature, there are no cases reporting bilateral cutaneous malignant melanoma. We report a singular case of a 43-year-old woman with two primary bilateral melanomas localized on the flexural surface of both legs.
\end{abstract}

\section{Case Report}

A 43-year-old woman presented to our outpatient clinic with two bilateral and irregularly pigmented lesions on the flexural surface of both legs (Figure 1). The first one, measuring $2.5 \times 2 \mathrm{~cm}$, was nodular and asymmetric with imprecise margins; it was localized on the sural region of the left leg (Figure 2). The second lesion, measuring about $3 \mathrm{~cm}$ in diameter, was flat, patchy pigmented and irregularly shaped (Figure 3); it was localized on the same area of the right leg. The patient reported that the lesion sited on the flexural surface of her lower left leg had appeared three years before as a flat, pigmented and asymptomatic patch, measuring about $5 \mathrm{~mm}$. In addition she related that this lesion had became larger within a few months and that a similar lesion had appeared on the same area of her right leg almost 1 year later. The patient had fair skin, red head, freckles on the chin, numerous solar lentigoes and melanocytic naevi on the décolleté and on the back: we categorized her skin type as phototype II according to Fitzpatrick skin phototype classification. ${ }^{1}$ No other suspicious skin lesions or palpable lymph nodes were detected. The patient had no personal or family history of relevant medical significance, apart from frequent sun burns during childhood. All the clinical features of the two pigmented lesions indicated the diagnosis of malignant melanoma (MM). Dermoscopic examination of both le- sions revealed: irregularly pigment network with atypical net ridges, blue-grey areas of regression, polymorphous vascular pattern, brown and black globules haphazardly distributed. All these features supported our clinical diagnosis of MM. Surgical excision of both lesions was performed. Histological examination confirmed the clinical diagnosis: the left lesion was micro-ulcerated, in radial and vertical growth infiltrating the reticular derma, Breslow's index $3 \mathrm{~mm}$ and Clark level III. This lesion was classified pt3bNxMx following the tumor-nodes-metastases (TNM) classification and stage II following the American Joint Committee on Cancer (AJCC). The lesion on the right leg had a pagetoid distribution infiltrating down the junction within the papillary and the reticular derma: Breslow's index 1.9 mm, Clark level III, TNM score pt2aNxMx and AJCC stage II. The sentinel lymph nodes localized in the popliteal fossa were removed. They were both negative. The patient was admitted to our day hospital for further examination because of the advanced Melanoma's stage. Laboratory studies were normal: full blood count (FBC), liver function test, electrolytes, tumor markers; abdominal and chest computerized tomographic (CT) scan revealed no pathological findings, whereas bone scintigraphy showed an irregular distribution of the radiocomponent on the lumbar spine; cranial and spine CT scan were normal. We sent her for an oncological consult: low dose Interferon alpha therapy was suggested. MM is the most common cancer in women aged from 25 to 29 years $^{2}$ and the eighth most common cancer in European women. ${ }^{3}$ Its incidence is increasing rapidly and it has been demonstrated that this is related to sun exposure. ${ }^{4}$ Large retrospective reviews show that the incidence of Multiple Primary Melanomas (MPM) ranges from 0.5\% to $8 \%$ between 1993 and $2003 .^{6-10}$ It is controversial if it depends on a better and earlier detection, rather than on a increased exposure to differential risk factors. These reviews also show that the incidence of MPM is increased in patients with dysplastic nevi and with posi-

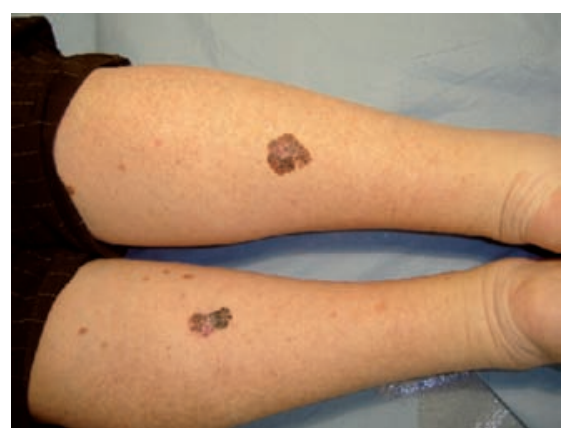

Figure 1. Bilateral and irregularly pigmented lesions localized on the flexural surface of both legs.
Correspondence: Serena Lembo, Department of Dermatology, University of Naples Federico II, via Pansini 5, 80131 Napoli, Italy.

Tel. +39.081.7462457 - Fax: +39.081.7462442.

E-mail: serenalembo@yahoo.it

Key words: malignant melanoma, dermoscopy, pigmented lesion, skin cancer.

Conflict of interest: none declared (the authors report no conflict of interest).

Received for publication: 21 July 2011.

Accepted for publication: 10 August 2011.

This work is licensed under a Creative Commons Attribution NonCommercial 3.0 License (CC BYNC 3.0).

(C) Copyright S. Lembo et al., 2011

Licensee PAGEPress, Italy

Dermatology Reports 2011; 3:e20

doi:10.4081/dr.2011.e20

tive family history. Genetic testing and intensive dermatologic screening should be performed on these high risk patients. ${ }^{10}$ Although few cases of bilateral uveal or choroidal melanoma are described in literature ${ }^{11,12}$ there are no cases reporting bilateral cutaneous MM. The peculiarity of the case we reported lays in the rare bilateral and symmetrical distribution of two primary malignant melanomas on the

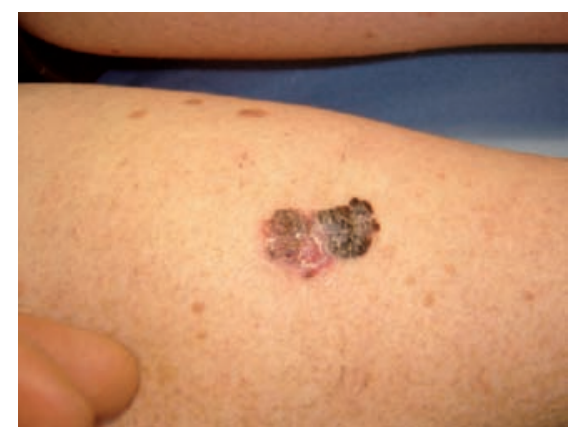

Figure 2. Nodular, pigmented and asymmetric lesion on the left leg.

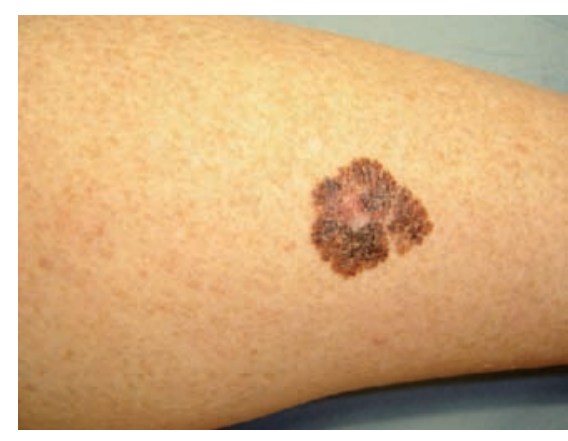

Figure 3. Flat, pigmented and irregularly shaped lesion on the right leg. 
legs. Moreover this case underline the need of spread and accurate educational campaigns aimed to the prevention and early detection of skin malignancies.

\section{References}

1. Roberts WE. Skin type classification systems old and new. Dermatol Clin 2009;27: 529-33.

2. Bataille V, de Vries E. Melanoma-part 1: epidemiology, risk factors, and prevention. BMJ 2008;337:1287-91.

3. Giblin AV, Thomas JM. Incidence, mortality, and survival in cutaneous melanoma.
J Plast Reconstr Aesthet Surg 2007;60:32-40.

4. Cataruzza MS. The relationship between melanoma and continuous or intermittent exposure to UV radiation. Arch of Dermatol 2000;136:773-4.

5. Slingluff CL Jr, Vollmer RT, Seigler HF. Multiple primary melanoma: incidence and risk factors in 283 patients. Surgery 1993;113:330-9.

6. Brobeil A, Rapaport D, Wells K, et al. Multiple primary melanomas: implications for screening and follow-up programs for melanoma. Ann Surg Oncol 1997;4:19-23.

7. Johnson TM, Hamilton T, Lowe L. Multiple primary melanomas. J Am Acad Dermatol 1998;39:422-7.

8. Blackwood MA, Holmes R, Synnestvedt M, et al. Multiple primary melanoma revisited. Cancer 2002;94:2248-55.

9. Goggins WB, Tsao H. A population-based analysis of risk factors for a second primary cutaneous melanoma among melanoma survivors. Cancer 2003;97:639-43.

10. Ferrone CR, Ben Porat L, Panageas KS et al. Clinicopathological features of and risk factors for multiple primary melanomas. JAMA. 2005;294:1647-54.

11. Bhouri L, Lumbroso L, Levy C. Bilateral uveal melanomas. Five case reports. J Fr Ophtalmol 2003;26:149-53.

12. Ruiz RS, El-Harazi SM, Kellaway J. Bilateral malignant melanoma of the choroid in the United States. Ophthalmologica 1998; 212:206-7. 